Article

\title{
Stray Flux Sensor Core Impact on the Condition Monitoring of Electrical Machines
}

\author{
Pengfei Tian ${ }^{1}$, Carlos A. Platero ${ }^{1, * \mathbb{C}}$, Konstantinos N. Gyftakis ${ }^{2} \mathbb{C}$ and Jose Manuel Guerrero ${ }^{1}$ \\ 1 Department of Automatic Control, Electrical and Electronic Engineering and Industrial Informatics, \\ Universidad Politécnica de Madrid, 28040 Madrid, Spain; tpf1213@gmail.com (P.T.); \\ josemaguerrero2@hotmail.com (J.M.G.) \\ 2 School of Engineering, The University of Edinburgh, Edinburgh EH8 9YL, UK; k.n.gyftakis@ieee.org \\ * Correspondence: carlosantonio.platero@upm.es
}

Received: 16 December 2019; Accepted: 26 January 2020; Published: 29 January 2020

\begin{abstract}
The analysis of the stray flux for electrical machine condition monitoring is a very modern and active research topic. Thanks to this technique, it is possible to detect several types of failures, including stator and rotor inter-turn faults, broken rotor bars and mechanical faults, among others. The main advantages are that it involves a non-invasive technique and low-cost monitoring equipment. The standard practice is to use coreless flux sensors, with which the stray flux of the machine is not perturbed and there are no problems due to saturation or nonlinear behavior of the iron. However, the induced voltage in the coreless coil sensor may be very low and even, in some cases, have a similar amplitude to the noise floor. This paper studies the use of iron core stray flux sensors for condition monitoring of electrical machines. The main advantage of iron core flux sensors is that the measured electromotive force is stronger. In the case of large machines in noisy environments, this can be crucial. Two different types of iron core stray flux sensors and a coreless flux sensor are tested. A comparison of the three sensors is presented. Extensive experimental testing with all sensors shows the superiority and greater sensitivity of sensors with core versus the coreless ones.
\end{abstract}

Keywords: electrical machine condition monitoring; field winding inter-turn fault; stray flux; stray flux sensor; stator inter-turn fault

\section{Introduction}

Detection of electrical machine faults via the stray flux has become a very modern and active research topic, as many early faults that create a magnetic asymmetry in the machines have become possible to detect [1].

In the case of induction machines, many different cases, such as broken rotor bars [2], inter-turn faults [3], problems in the bearings [4] and even the insulation's health and ageing can be detected [5]. For these purposes, several techniques have been applied to analyze the stray flux, such as the bispectrum and covariance [6], the correlation coefficients [7] and the frequency extraction [8]. In some cases, two or more flux sensors are used $[3,7,8]$. The mechanical speed frequency also has an important role in rotor electrical and eccentricity fault detection [9]. Additionally, finite element method (FEM) studies have been performed studying the impact of different faults on the stray flux in induction machines $[10,11]$.

In cases of permanent magnet synchronous machines, the stray flux has been used not only for fault detections [12] but also to measure the rotation speed [13].

Conventional rotor-wounded synchronous machines are the most important machines in power generation. The stray flux analysis may be a reliable method to detect early faults in such electrical 
machines. Past works suggest that inter-turn faults in both the rotor and the stator can be detected reliably $[14,15]$.

Throughout the literature, the most frequently used flux sensors to measure the stray flux in electrical machines are coreless coils, normally known as research coils [1,2,4-9]. Some authors use rectangular-shaped coils [14,15]. Only a few authors use other types of sensors such as giant magneto resistive (GMR) [1] or tunneling magneto resistive sensors (TMR) [12,13].

The general operation principle dictates that the sensors supply an induced voltage, which is proportional to the derivative of the flux. The induced voltage is then recorded and analyzed with appropriate signal processing methods. The positioning of the sensor on the machine is also important as it can lead to the measurement of either the axial or the radial component of the stray flux.

Other industrial sensors, not often used for electrical machine monitoring, are the flux gate sensors or the hall effect sensor [16]. However, many researchers design their own sensors adapted to the size of the machine.

In other industrial applications the development of new magnetic field sensors is an ongoing research field. The use of microwires [17], the delta-E effect [18] and the magnetic flux leakage sensor [19] are some of the recent novelties in the area.

The most widespread sensor for electrical machine monitoring is the air core type, mainly for two reasons. This sensor type does not modify the stray flux of the machine, and the measurements are not influenced by the nonlinear behavior of the iron core due to the permeability, saturation, hysteresis or eddy currents. On the other hand, as the stray flux may have a low amplitude, the voltage induced in the sensor may also be small. Therefore, a large number of turns is required.

In this paper, two different topologies of iron core stray flux sensors are presented and tested in the laboratory with a special synchronous machine. The magnetic core of the machine is modified by the iron of the sensor, and consequently the stray flux changes. The main advantage of the iron core sensors is that the induced voltage is significantly higher than in an air core sensor.

After a thorough experimental investigation, the conclusion is that the operation of the iron core stray flux sensor is appropriate, and the faults are detected more accurately than with conventional sensors.

\section{Materials and Methods}

\subsection{Air and Iron Core Stray Flux Sensors}

The sensors used in this work were manufactured with a rectangular shape and comprise 200 turns of copper wire. The coils were placed in similar dielectric supports. Then at a second stage, the three individual coils were further discriminated by the use or not of an iron core. The first coil formed a coreless flux sensor. For the other two sensors, the coils were mounted on iron cores, with $U$ and $E$ shapes, respectively. The iron cores were built by standard magnetic steel laminations used in small transformers. The sensor coil supports are shown in Figure 1. 


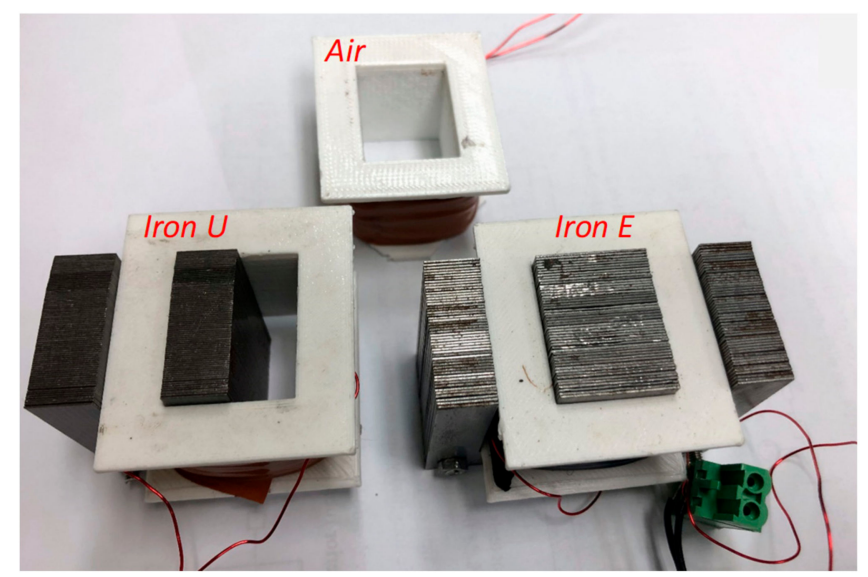

Figure 1. Flux sensors: Air, iron core U and iron core E.

The dimensions of the sensors are presented in Figure 2. The dimensions of the laminations are displayed in Figure 3. All the geometrical data of the sensors are presented in Table 1. The measurement system was just an oscilloscope which recorded the induced voltage in the sensors. Afterwards, the records were analyzed with MATLAB software in a computer.

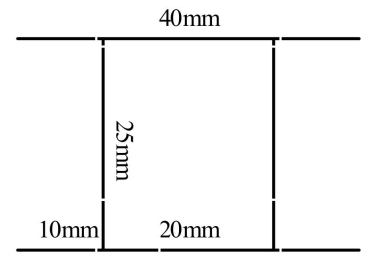

Side View

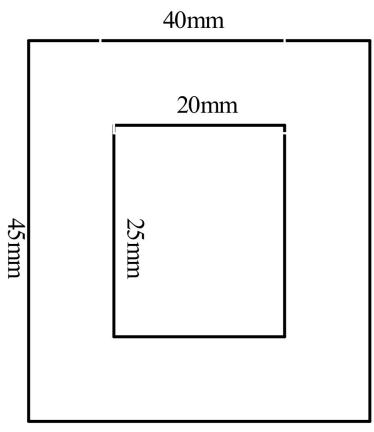

Top View

Figure 2. Side and top views of the coil support.
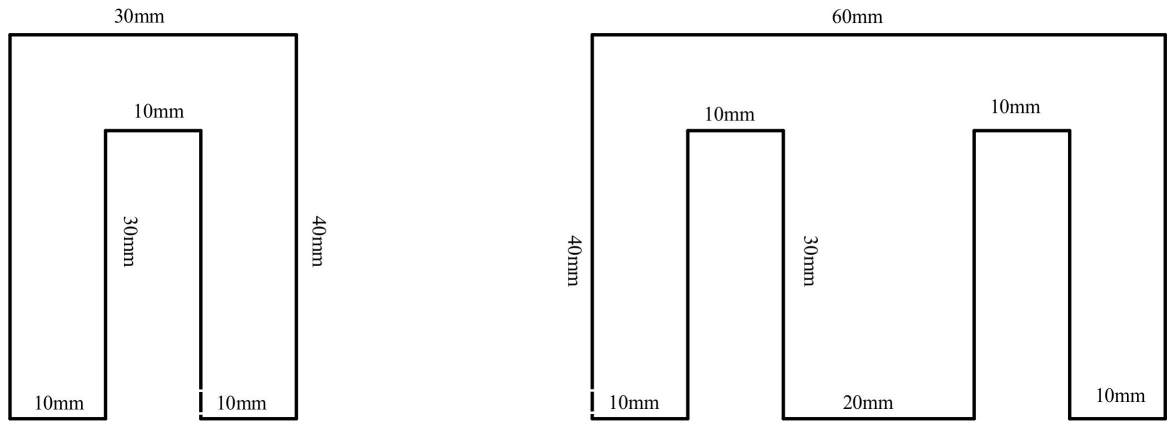

Figure 3. Dimension of magnetic steel lamination shape $U$ and E.

The stray fluxes in the three sensors were different. In the case of the air core sensor, the stray flux was not distorted in any way. On the other hand, the iron cores increased the magnetic flux density due to the low permeability of the new flux path. Consequently, the sensors' output voltage amplitude was significantly greater with iron core sensors. 
Table 1. Sensor data.

\begin{tabular}{cccc}
\hline Type of Sensor & Iron E & Iron U & Air \\
\hline Copper Turns & 200 & 200 & 200 \\
Box Length (mm) & 45 & 45 & 45 \\
Box Width (mm) & 40 & 40 & 40 \\
Box Height (mm) & 25 & 25 & 25 \\
Hollow Length (mm) & 26 & 26 & 26 \\
Hollow Width (mm) & 20 & 20 & 20 \\
Iron U Length (mm) & & 40 & \\
Iron U Width (mm) & & 30 & \\
Iron U Foot Width (mm) & & 10 & \\
Iron E Length (mm) & 40 & & \\
Iron E Width (mm) & 60 & & \\
Iron E Right and Left & 10 & & \\
Foot Width (mm) & & & \\
Iron E Middle Foot & 20 & & \\
Width (mm) & &
\end{tabular}

\subsection{Laboratory Experimental Setup}

This section describes the experimental setup for testing the three stray flux sensors. The tests were performed in a specially reconfigured synchronous machine where it was possible to carry out different electrical faults in the rotor and the stator.

In Figures 4 and 5, the electrical connection schemes of the stator and rotor are shown, respectively. The stator phase $C$ has partial windings taps, which make it possible to perform inter-turn faults of variable severity in the stator (Figure 4). Additionally, the salient pole connections were reachable through a hole in the shaft, so inter-turn rotor faults of varied severity could be emulated by the use of the variable fault resistance $R_{F}$ (Figure 5).

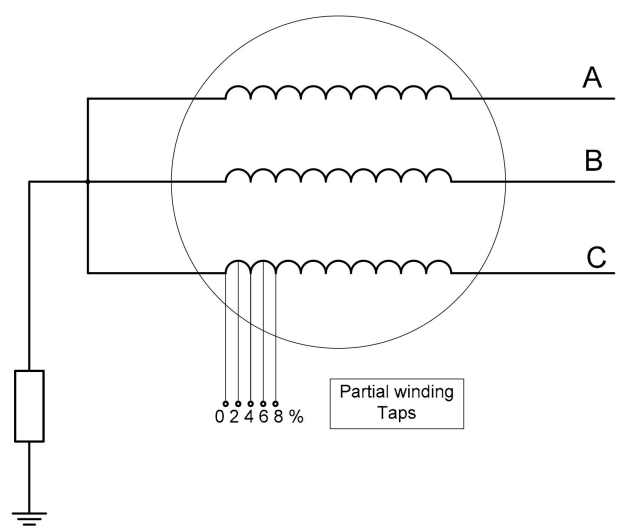

Figure 4. Synchronous machine stator connections.

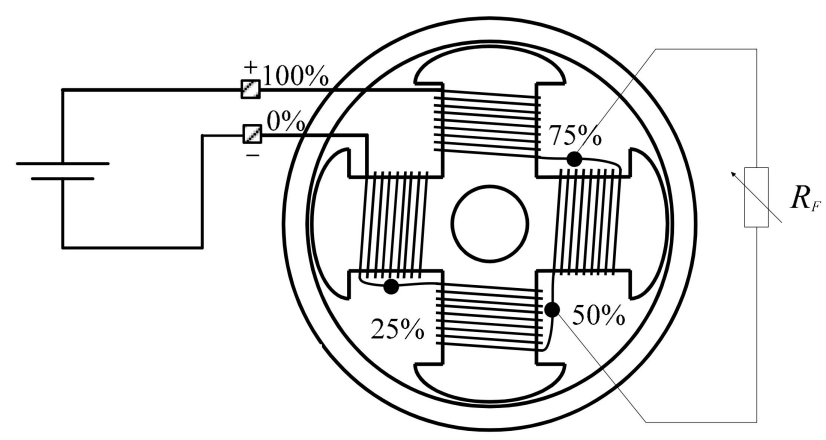

Figure 5. Synchronous machine rotor connections. 
The complete experimental test bed is shown in Figure 6. The synchronous machine (1) was driven by an induction motor (2) fed by a frequency converter (3). The excitation of the machine was connected to an adjustable DC voltage source (4). The machine was connected to the power system by a panel (5) featuring a synchronizer. In this particular test, an iron core stray flux sensor with an E shape was placed in the upside part of the machine (6). Other tests were performed with the sensor placed in the right side of the machine. The induced voltage in the sensor was recorded in an oscilloscope (7).

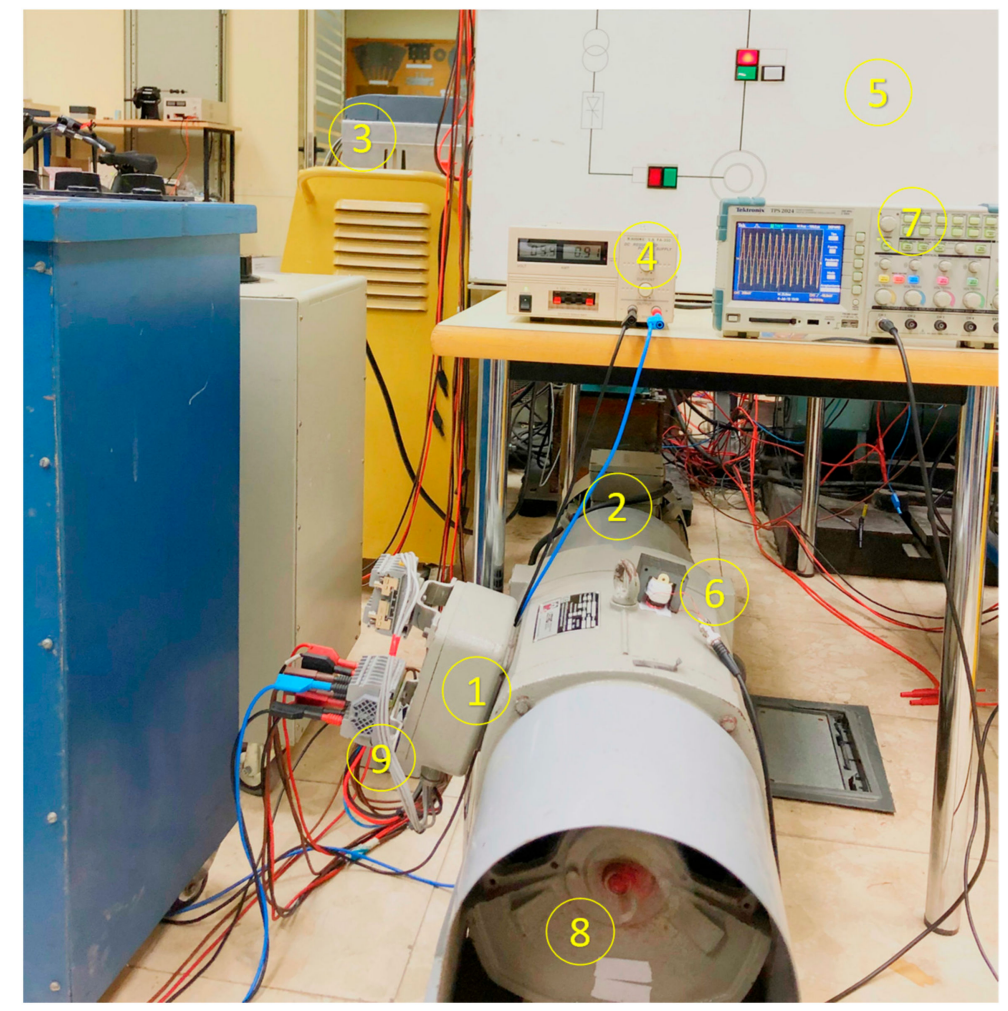

Figure 6. Experimental setup. (1) Synchronous machine, (2) asynchronous motor, (3) frequency converter, (4) DC-adjustable voltage source for excitation, (5) connection panel with synchronizer, (6) iron core E-type flux sensor, (7) oscilloscope, (8) pole connections and (9) stator tap terminals.

As explained before, the pole connections were accessible in the shaft (8). In the connections, different resistances $\mathrm{R}_{\mathrm{F}}$ were connected to emulate inter-turn faults. On the other hand, there were additional terminals with the taps of the stator phase $C$ (9). The rated parameters of the special synchronous machine are shown in the Appendix A.

The synchronous machine was synchronized and connected to the grid. The active and reactive powers were controlled by the frequency converter (3) and the DC-adjustable voltage source (4), respectively.

\section{Results}

In this section, the results of the different tests under different conditions are presented. The first set of tests was performed with the healthy machine. The second set of tests corresponds to the machine with rotor inter-turn fault with different fault severities. This fault produced an imbalance related to the mechanical frequency, which in this case was $25 \mathrm{~Hz}$. Finally, the third set of tests corresponds to inter-turn fault in the stator. This fault normally produces a signature at $850 \mathrm{~Hz}$ and $950 \mathrm{~Hz}$. These frequencies $\left(f_{\text {SISC }}\right)$ are related to the electrical frequency $\left(f_{1}\right)$ multiplied by number of stator slots $(k)$ 
divided by the pair poles (p), according to Equation (1). In this case, the stator slots were 36 and the pole pairs were 2, while the electrical frequency was $50 \mathrm{~Hz}$.

$$
f_{\text {SISC }}=\left[\frac{k}{p} \pm 1\right] f_{1}
$$

\subsection{Healthy Condition}

This section presents the results of the three sensors measuring stray flux in a laboratory synchronous machine in healthy conditions in two different positions, one in the upper part of the machine and the other in one side, as explained in the previous section.

In Figure 7, the induced voltages in the three flux sensors are presented. In the case of the healthy machine, the main component of the voltage corresponds to the $50 \mathrm{~Hz}$ frequency harmonic, as shown in Figure 8. As it can be clearly observed in Figures 7 and 8, the signals and their respective harmonic components were similar. However, the voltage amplitudes offered by the iron core sensors were between four and seven times greater than those offered by the air core sensor.

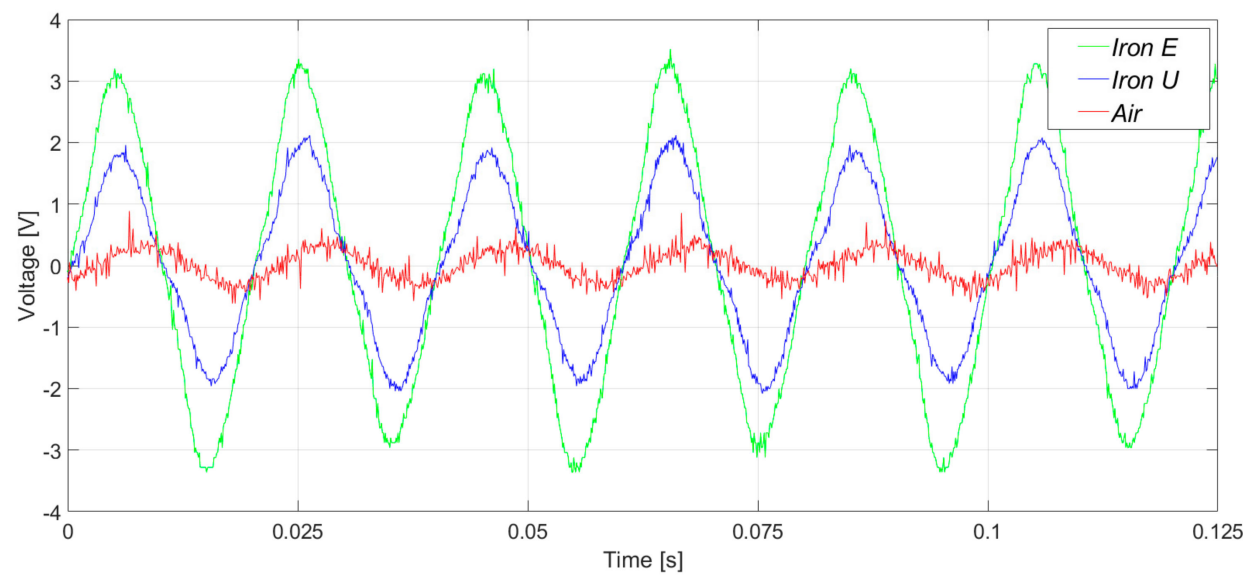

Figure 7. Induced voltage measurement in healthy conditions, in the right-side position.

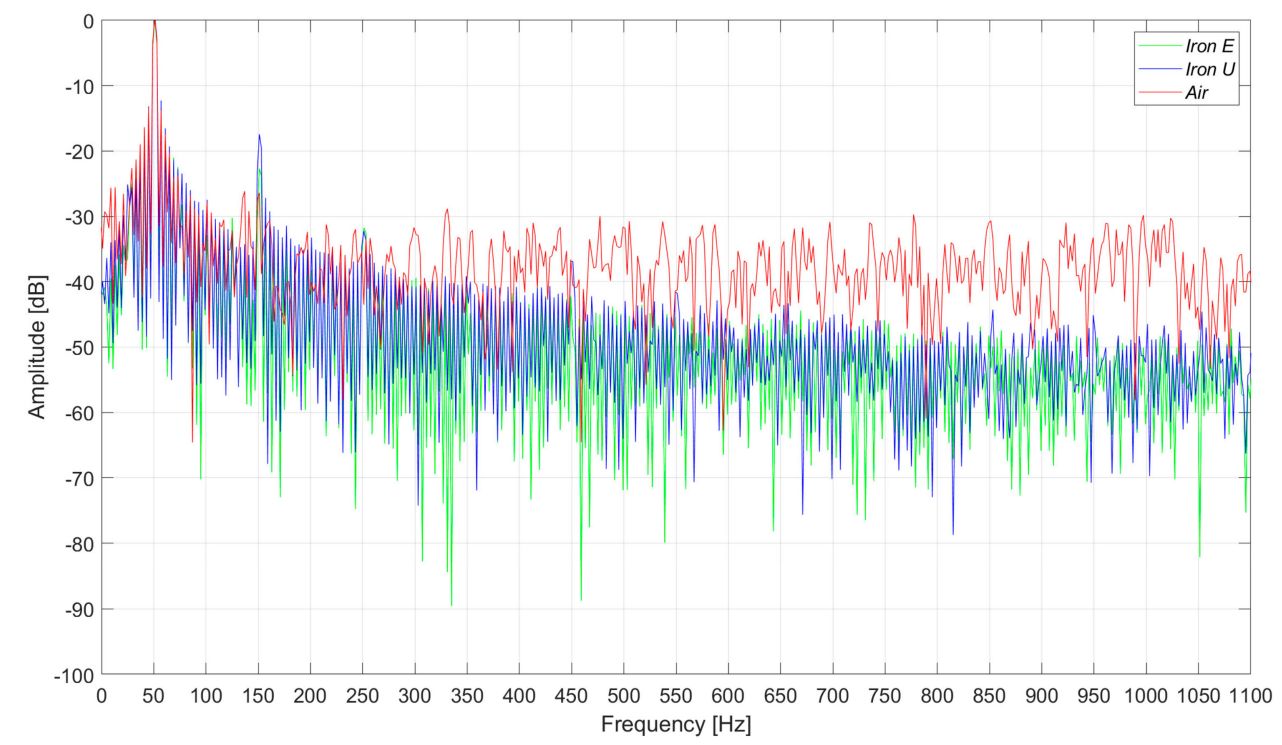

Figure 8. Frequency analysis of the induced voltage measurement in healthy conditions, in the right-side position. 
The measurements were taken in a laboratory where there were some electronic power converters in operation. Consequently, the three sensors had a high noise floor. However, the noise influenced the case of the air core sensor the most (Figures 9 and 10). In Figures 9 and 10, the induced voltages and the harmonics analysis are presented for the case of the healthy machine with the flux sensors placed in the upside position.

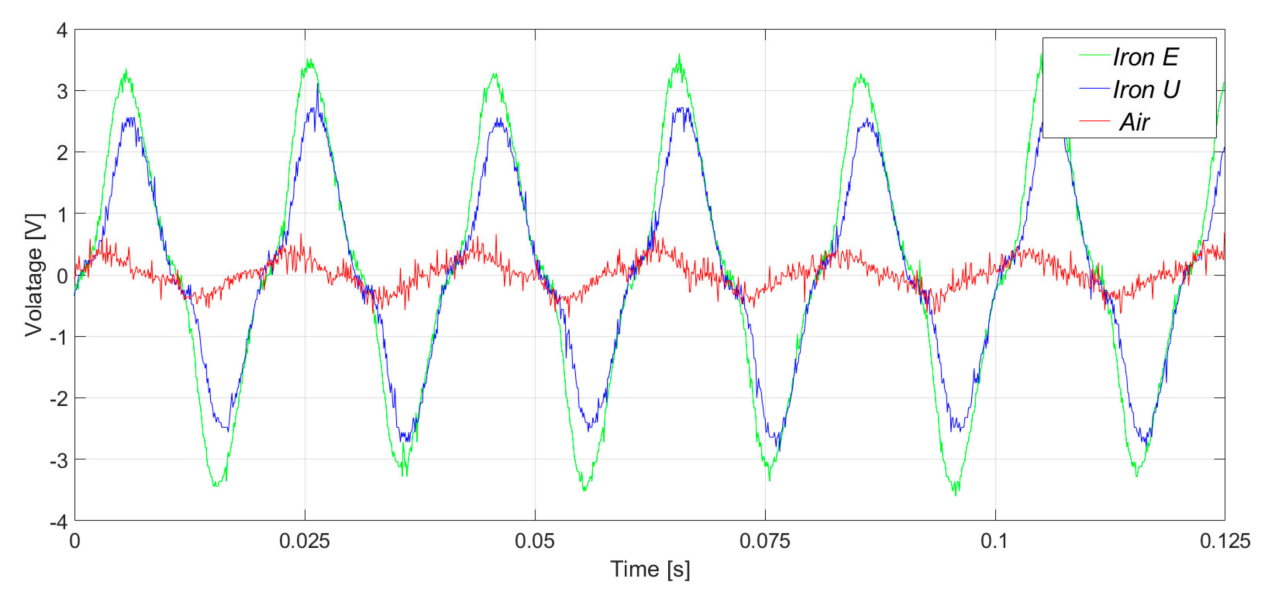

Figure 9. Induced voltage measurement in healthy conditions, in the upside position.

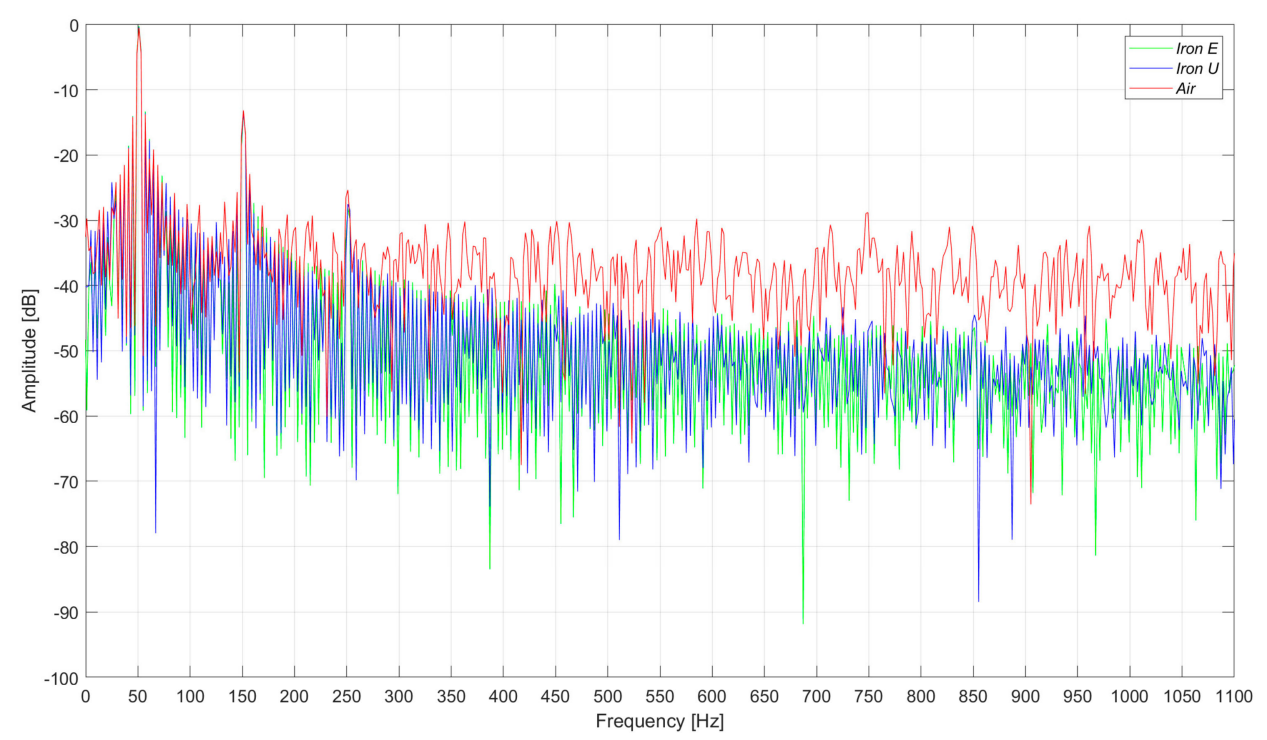

Figure 10. Frequency analysis of the induced voltage measurement in healthy conditions, in the upside position.

Table 2 shows the results obtained by the three sensors under healthy conditions at different positions. A comparison between the $50 \mathrm{~Hz}$, the $25 \mathrm{~Hz}$ and the $850 \mathrm{~Hz}$ components are presented, as these frequencies are typical in the rotor and stator inter-turn faults.

Table 2. Results of healthy condition.

\begin{tabular}{ccccccc}
\hline Condition & \multicolumn{3}{c}{ Healthy Upside } & \multicolumn{3}{c}{ Healthy Right Side } \\
\hline Type of Sensor & Iron E & Iron U & Air & Iron E & Iron U & Air \\
\hline Max Voltage [V] (Abs value) & 3.6 & 3.12 & 0.824 & 3.52 & 2.88 & 0.888 \\
Amplitude at 50 Hz [dB] & 0 & 0 & 0 & 0 & 0 & 0 \\
Amplitude at 25 Hz [dB] & -26 & -26 & -24 & -25 & -26 & -23 \\
Amplitude at $850 \mathrm{~Hz}[\mathrm{~dB}]$ & -46 & -44 & -32 & -40 & -44 & -33 \\
\hline
\end{tabular}




\subsection{Rotor Inter-Turn Faulty Conditions}

This subsection presents the results from the three sensors measuring stray flux analysis in the case of rotor inter-turn faults with $5 \%$ and $15 \%$ of fault severity.

In the case of an inter-turn fault, one of the poles of the machine had a lower number of winding turns in operation. Consequently, a magnetic imbalance was created, as one of the poles produced a lower magnetomotive force than the others. Under such conditions, a harmonic corresponding to the rotating frequency is expected to appear in the stray flux of the stator [14,15].

In Figure 11, the induced voltages recorded by the three sensors are presented for operation under $5 \%$ rotor inter-turn fault. While the machine had four poles, the rotating mechanical frequency was $25 \mathrm{~Hz}$. The corresponding harmonic analysis is displayed in Figure 12 for all sensor cases.

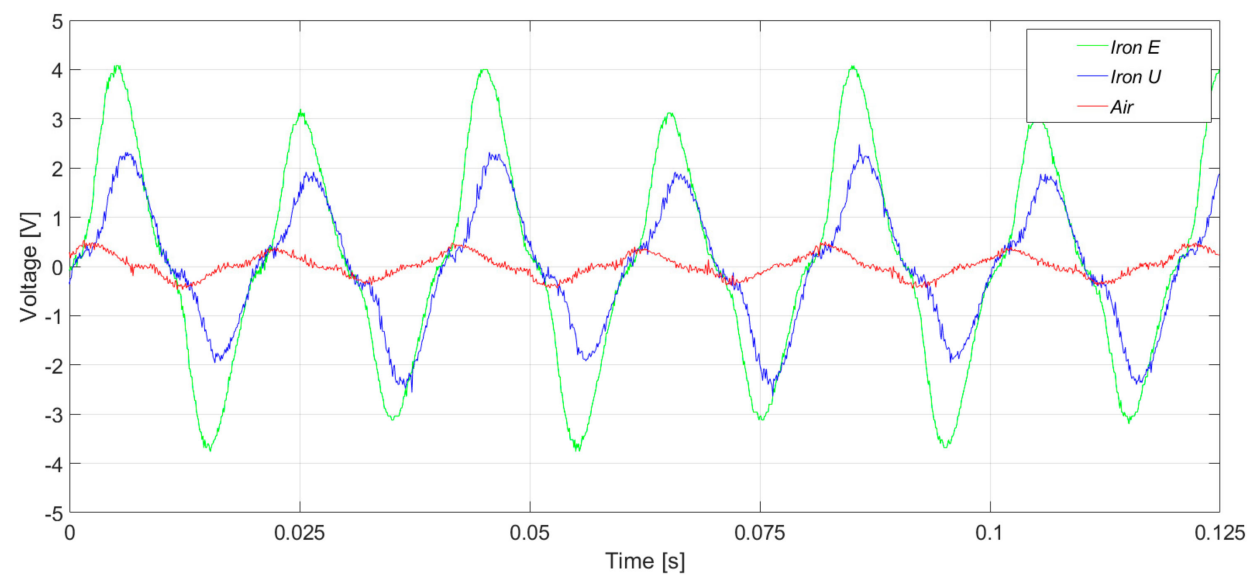

Figure 11. Induced voltage measurement with a $5 \%$ inter-turn rotor fault severity, in the upside position.

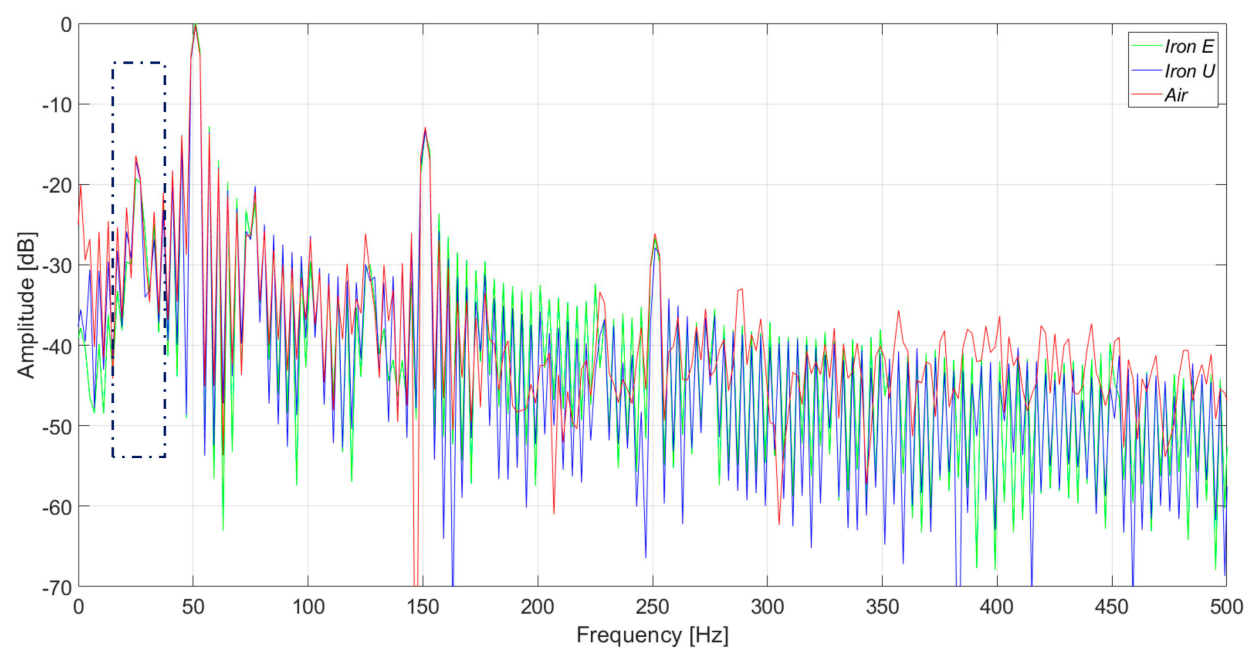

Figure 12. Frequency analysis of the induced voltage measurement with a $5 \%$ inter-turn rotor fault severity, in the upside position.

The induced voltage amplitude was greater in the case of iron core sensors than it was for air core sensors, especially in the E-shape type. Moreover, the calculated spectra were similar. It could be clearly seen that the $25 \mathrm{~Hz}$ harmonic, corresponding to the inter-turn fault in the field winding, presented an increased amplitude compared to the healthy machine. In Figures 13 and 14, the induced voltage and the harmonics analysis in the three sensors are presented, respectively, for a $15 \%$ rotor inter-turn fault. The results were close to those presented above, but the amplitudes of the $25 \mathrm{~Hz}$ components were greater than in previously studied cases, as expected. 


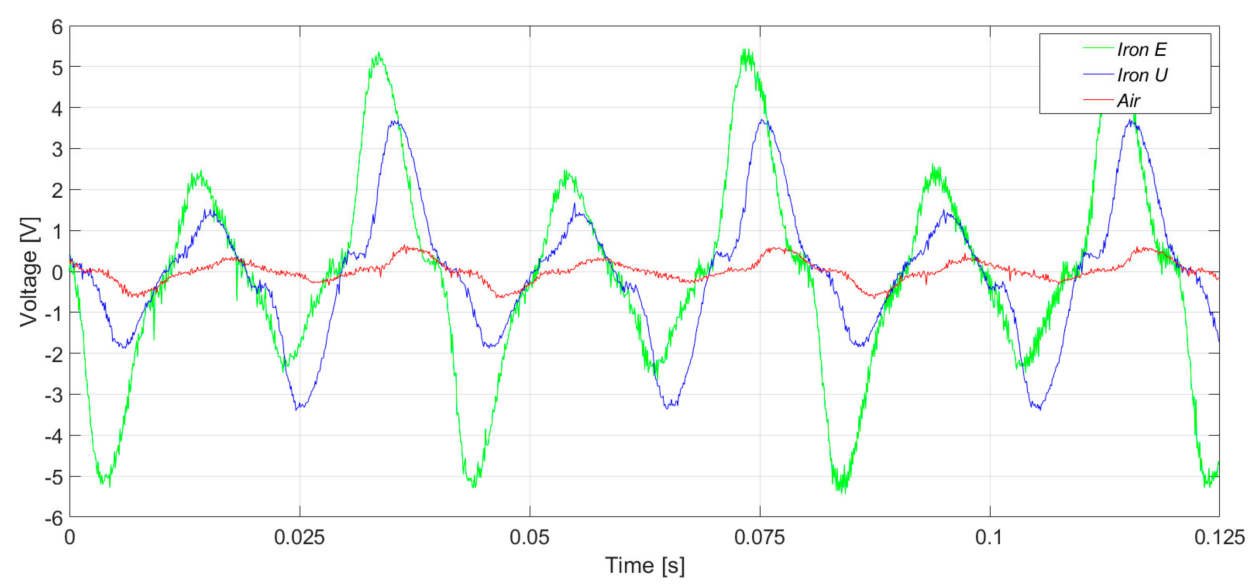

Figure 13. Induced voltage measurement with a $15 \%$ inter-turn rotor fault severity, in the upside position.

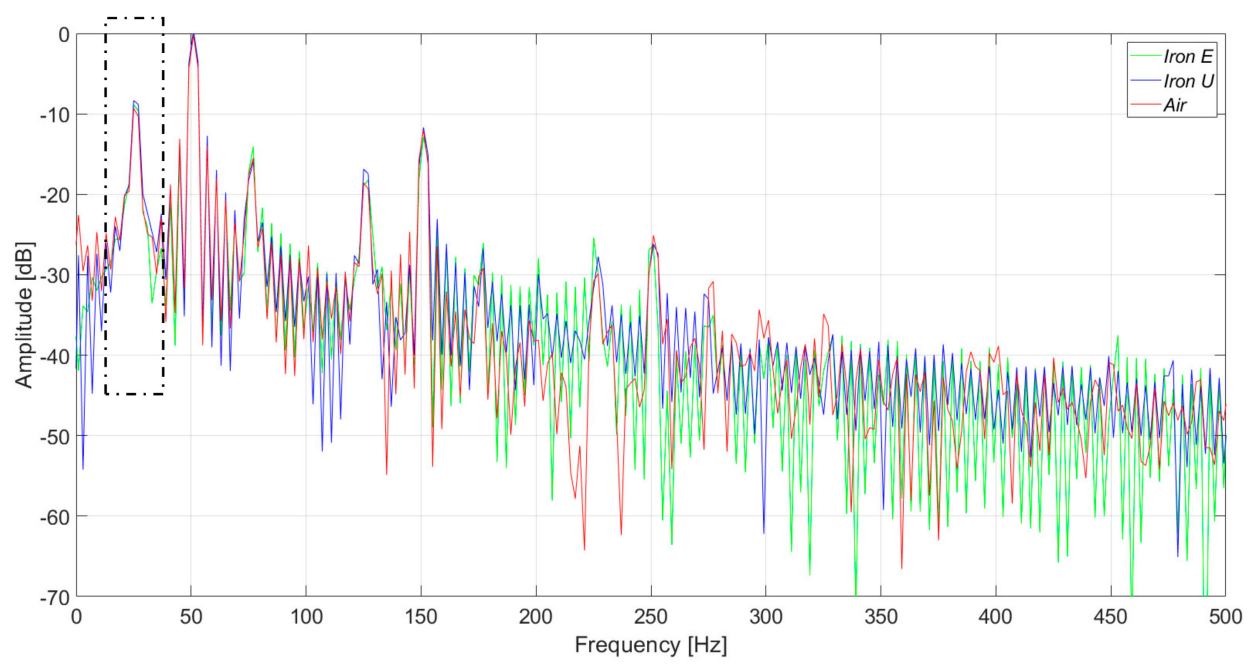

Figure 14. Frequency analysis of the induced voltage measurement with a $15 \%$ inter-turn rotor fault severity, in the upside position.

From Table 3, it can be clearly seen that the $25 \mathrm{~Hz}$ component could be detected by the three sensors. Furthermore, the amplitude differences between the fundamentals at $50 \mathrm{~Hz}$ and the $25 \mathrm{~Hz}$ signatures were similar. However, the induced voltage amplitude in the iron core $\mathrm{E}$ shape was eight time greater than in the case of the air core.

Table 3. Results of rotor inter-turn fault.

\begin{tabular}{ccccccc}
\hline Condition & \multicolumn{3}{c}{ Rotor Inter-Turn 5\% } & \multicolumn{3}{c}{ Rotor Inter-Turn 15\% } \\
\hline Type of Sensor & Iron E & Iron U & Air & Iron E & Iron U & Air \\
\hline Max Voltage [V] (Abs value) & 4.08 & 2.64 & 0.56 & 5.68 & 3.76 & 0.72 \\
Amplitude at 50 Hz [dB] & 0 & 0 & 0 & 0 & 0 & 0 \\
Amplitude at 25 Hz [dB] & -17 & -17 & -17 & -7 & -9 & -10 \\
\hline
\end{tabular}

\subsection{Stator Inter-Turn Fault Conditions}

This section presents the results from the three sensors measuring stray flux analysis in a laboratory synchronous machine in the case of stator inter-turn faults. The severity level of the fault was set to $2 \%$ and $4 \%$ of the winding. In both cases, a $3 \Omega$ limiting resistor was connected with the shortened loop in order to limit the developed short current of high amplitude, so that the machine was kept safe from overheating and catastrophic damage. 
Figures 15 and 16 present the induced voltage waveforms in both the time domain and frequency domain under operation with $2 \%$ stator inter-turn fault. The synchronous machine tested had 36 stator slots and 2 pole pairs. Therefore, the 17th and the 19th harmonics were raised in the case of an inter-turn fault in the stator. In the case of iron core sensors, these harmonics were quite clear. However, the same harmonics were hidden in the noise floor for the case of the coreless sensor.

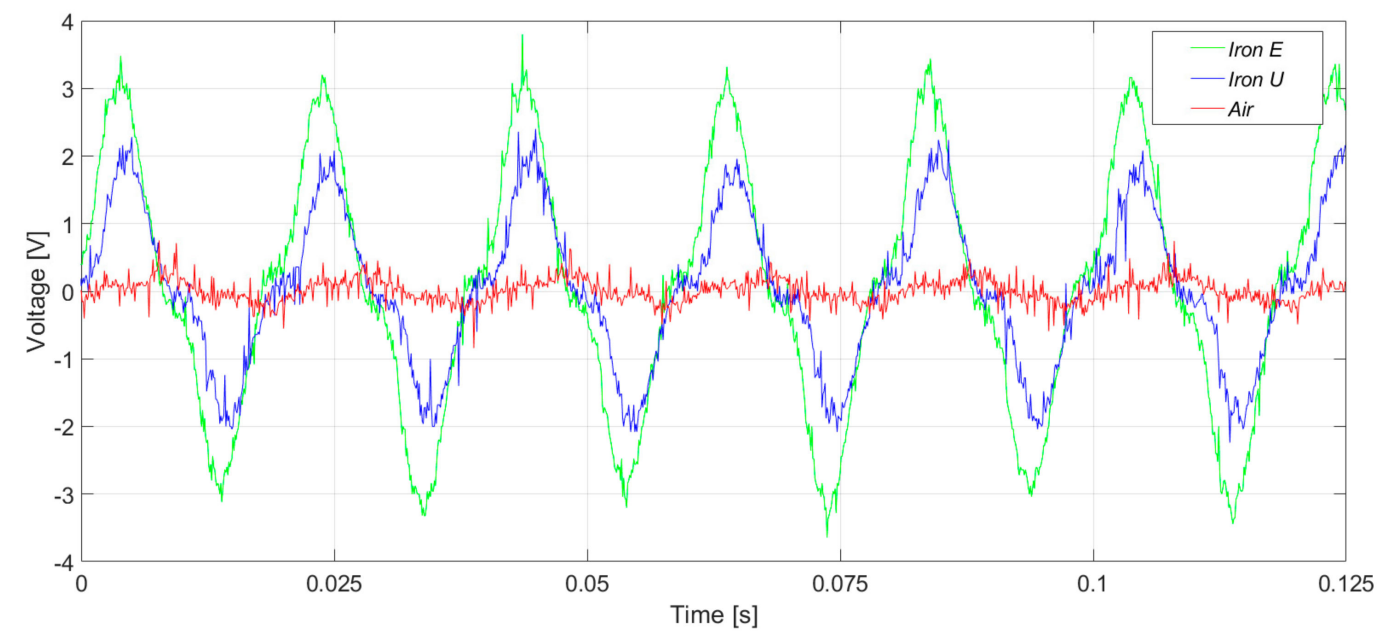

Figure 15. Induced voltage measurement with a $2 \%$ inter-turn stator fault severity, in the upside position.

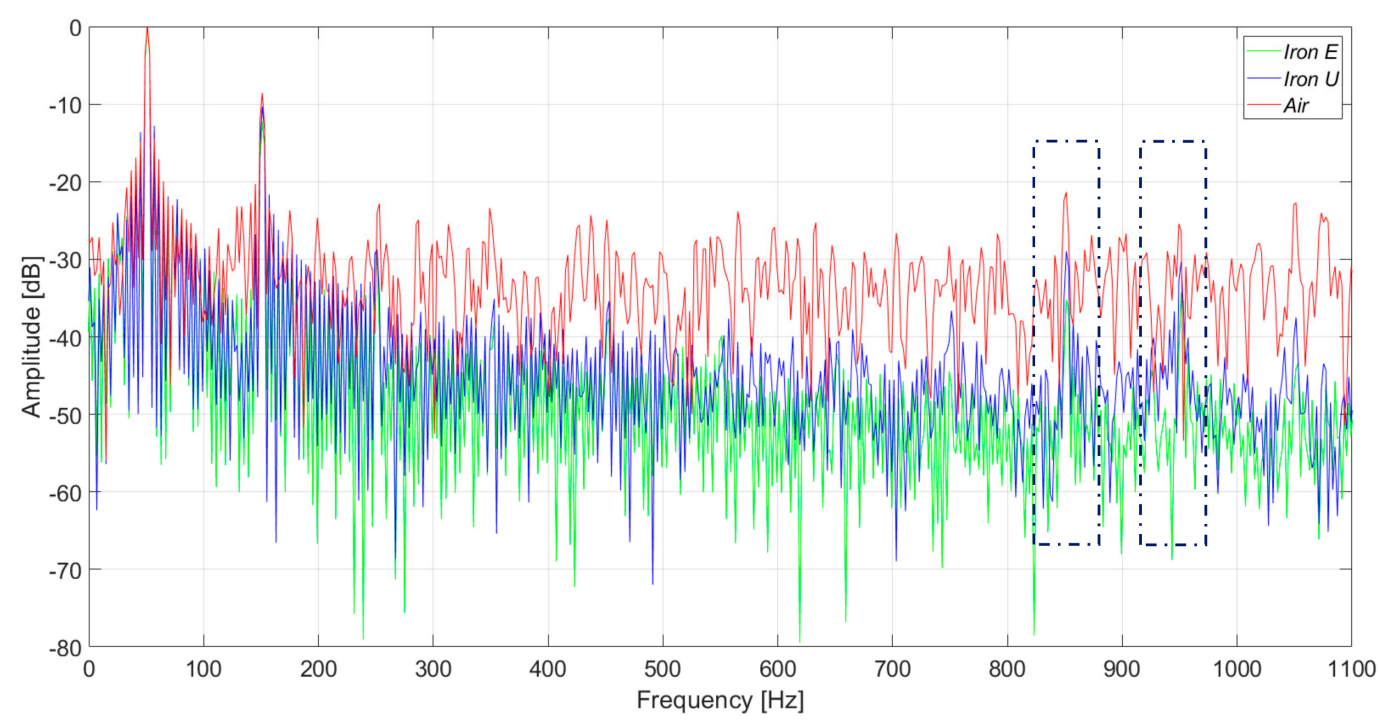

Figure 16. Frequency analysis of the induced voltage measurement with a $2 \%$ inter-turn stator fault severity, in the upside position.

In Figures 17 and 18, the induced voltage waveforms and the respective harmonics analysis for the three sensors are presented, respectively, for machine operation with a $4 \%$ stator inter-turn fault. The results were close to those presented above. The amplitudes of the 17th and 19th harmonics components were similar to those obtained for $2 \%$ fault severity, and the non-monotonous behavior was similar to the case of the induction machines [20]. 


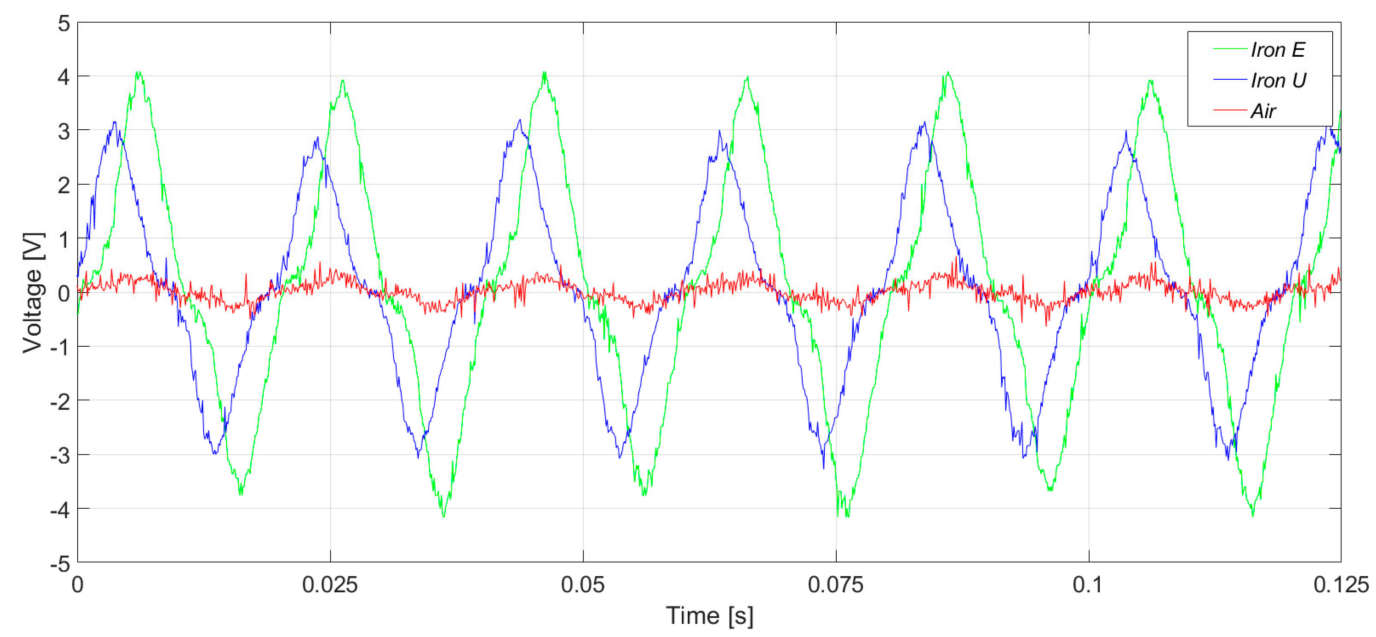

Figure 17. Induced voltage measurement with a $4 \%$ inter-turn stator fault severity.

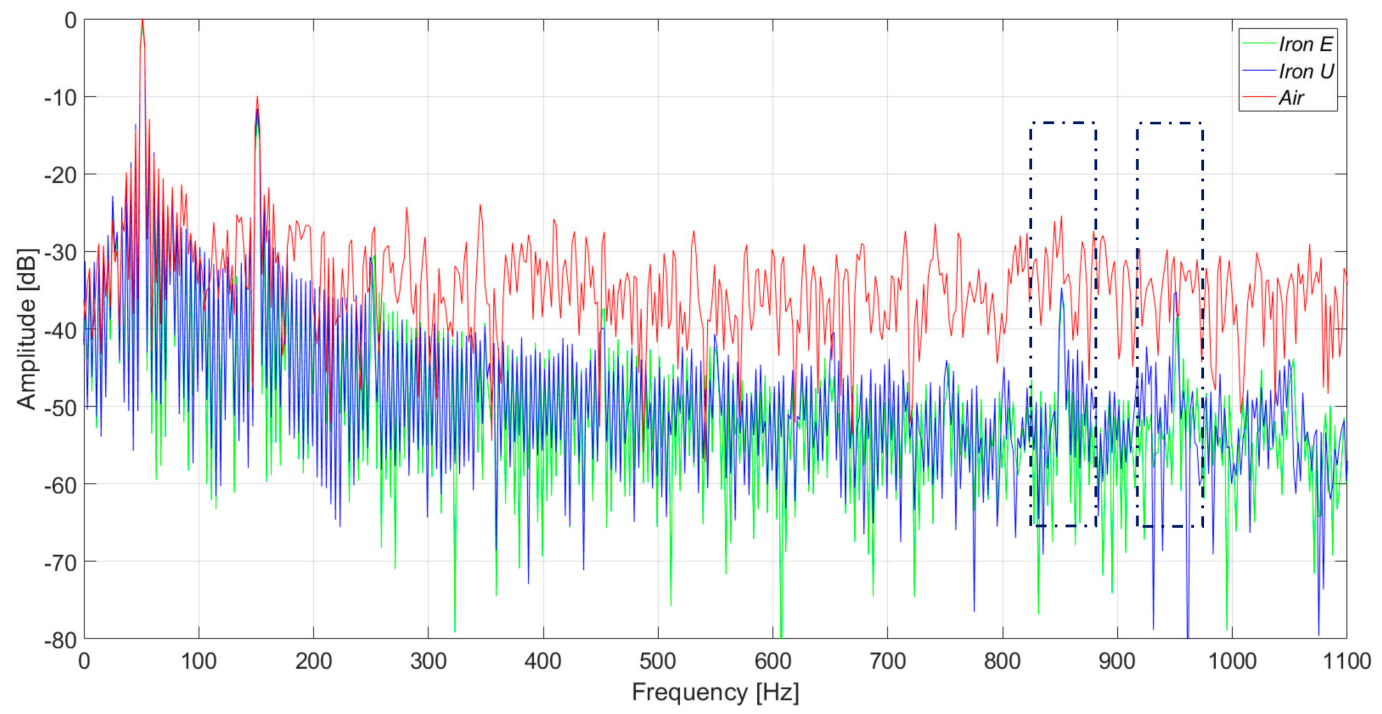

Figure 18. Frequency analysis of the induced voltage measurement with a $4 \%$ inter-turn stator fault severity.

The results analyses for machine operation under stator inter-turn faults are summarized in Table 4 for all used sensors and fault severity levels.

Table 4. Results of stator inter-turn fault.

\begin{tabular}{ccccccc}
\hline Condition & \multicolumn{3}{c}{ Stator Inter-Turn $\mathbf{2 \%}$} & \multicolumn{3}{c}{ Stator Inter-Turn 4\% } \\
\hline Type of Sensor & Iron E & Iron U & Air & Iron E & Iron U & Air \\
\hline Max Voltage [V] (Abs value) & 3.8 & 2.4 & 0.84 & 4.32 & 3.56 & 0.664 \\
Amplitude at 50 Hz [dB] & 0 & 0 & 0 & 0 & 0 & 0 \\
Amplitude at $850 \mathrm{~Hz}[\mathrm{~dB}]$ & -25 & -29 & -21 & -36 & -35 & -25 \\
\hline
\end{tabular}

\section{Discussion}

Air core sensors have been the usual solution in past works. The sensors consist of rigid coils with different shapes, either round or rectangular. The coils should have a high number of turns to increase the sensor's sensitivity, since the stray flux amplitude is very low due to the high magnetic reluctance between the stator iron core and the exterior of the machine. As a result, only a small fraction of the flux radiates outside the machine. 
In this paper, two different iron core stray flux sensors are presented and compared to an air core flux sensor with a similar number of turns. The iron core shapes used are $U$ and E, typically found in small transformers. At the beginning of this research, two different problems were expected. On one hand, the iron core of the sensor would modify the magnetic circuit when placed close to the machine. Consequently, the stray flux in this part of the machine would be different than in the rest. It was not certain that the assessment of the flux under such conditions could identify the faults. After the tests, we can conclude that the iron core stray flux sensor can identify the faults in exactly the same way as the conventional coreless one.

On the other hand, the saturation and the nonlinear behavior of the iron can modify the induced voltage in the sensor coil. According to the performed tests, the waveforms in the iron core sensor and in the air core sensor are similar for frequencies up to $300 \mathrm{~Hz}$. For frequencies above $300 \mathrm{~Hz}$, the iron core sensors have lower gains. But in the case of stator inter-turn faults, the 17th and 19th harmonics are better detected than in the case of the air core sensor.

The use of iron presents an important advantage. The induced voltages in the coil are greater than in the case of the air core sensor. In the executed tests, the obtained amplitudes are between four and seven times higher.

In Table 5, a summary of the results is presented. To evaluate the sensibility of the sensors, the amplitude differences of the various harmonics from their respective fundamentals are compared.

Table 5. Summary of the Results.

\begin{tabular}{cccc}
\hline Type of Sensor & Iron E & Iron U & Air \\
\hline Healthy & & & \\
Amplitude [dB] $(25 \mathrm{~Hz})$ & -26 & -26 & -24 \\
$\quad$ Rotor Inter-Turn $5 \%$ & & & \\
Amplitude [dB] $(25 \mathrm{~Hz})$ & -17 & -17 & -17 \\
$\quad \begin{array}{c}\text { Rotor Inter-Turn } 15 \% \\
\text { Amplitude [dB] }(25 \mathrm{~Hz})\end{array}$ & -7 & -9 & -10 \\
\hline$\quad \begin{array}{c}\text { Healthy } \\
\text { Amplitude [dB] }(850 \mathrm{~Hz})\end{array}$ & -46 & -44 & -32 \\
$\quad \begin{array}{l}\text { Stator Inter-Turn } 2 \% \\
\text { Amplitude [dB] }(850 \mathrm{~Hz}) \\
\quad \text { Stator Inter-Turn } 4 \%\end{array}$ & -25 & -29 & -21 \\
Amplitude [dB] $(850 \mathrm{~Hz})$ & -36 & -35 & -25 \\
\hline
\end{tabular}

In the case of the E-shape sensor, if an inter-turn fault happens in the rotor, the amplitude of the $25 \mathrm{~Hz}$ harmonic increases by $9 \mathrm{~dB}$ (from $-26 \mathrm{~dB}$ to $-17 \mathrm{~dB}$ ) for $5 \%$ and $19 \mathrm{~dB}$ (from $-26 \mathrm{~dB}$ to $-7 \mathrm{~dB}$ ) for $15 \%$ fault severity respectively. The obtained results by using the $U$ shape are similar, increasing by $9 \mathrm{~dB}$ and $17 \mathrm{~dB}$ for $5 \%$ and $15 \%$ inter-turn rotor faults, respectively. For the air core sensor, the increases are $7 \mathrm{~dB}$ and $14 \mathrm{~dB}$, respectively.

The inter-turn stator faults are undoubtedly better observed by using the iron core sensors. The amplitude increase of the 17th and 19th harmonics is remarkable when compared to the adjacent harmonics. This can be clearly seen in Figures 16 and 18. On the other hand, these harmonics are not so easily detected when the air core sensor is applied.

\section{Conclusions}

The normal practice in electrical machine monitoring is the use of air core flux sensors. After being mounted outside of the monitored machine, the induced voltage is recorded and analyzed. In this way, the stray flux of the machine is not perturbed, and there are no problems due to saturation or nonlinear behavior of the iron. However, the induced voltage may be weak, mainly due to the high reluctance between the actual stator iron core and the sensors. 
Instead, this paper proposes iron core stray flux sensors with E and U shapes for the same task. These sensors have been built with standard iron lamination used for small transformers. Although the magnetic circuit of the machine is slightly modified, as is the stray flux, the faults can be easily detected. The characteristic frequencies of the rotor and stator inter-turn fault can be clearly observed in the performed tests. On the other hand, the nonlinear behavior of the iron due to the permeability, saturation, hysteresis or eddy currents does not affect the fault detection.

Two different types of iron core stray flux sensors and an air core flux sensor were tested and compared. All sensors have the same geometry and number of turns in the rigid coil. The correct operation of the iron core stray flux sensors was validated by experimental results in a specially reconfigured synchronous machine where inter-turn faults were performed in the rotor and in the stator windings.

The analysis results suggest that the use of iron core flux sensors is advantageous. The main advantage is a significantly greater amplitude of the induced voltage for the same stray flux. This feature can be crucial for the case of large machines in noisy environments. Furthermore, the sensitivity of the iron core flux sensors to the signatures related with stator inter-turn faults was significantly greater than that of air core ones. Finally, in the case of rotor inter-turn faults, the use of the iron core sensor with an E shape offered slightly better results.

Author Contributions: Conceptualization, P.T. and C.A.P.; methodology, K.N.G. and C.A.P.; experimental validation, P.T. and J.M.G.; writing-original draft preparation, K.N.G. and C.A.P. All authors have read and agreed to the published version of the manuscript.

Funding: This work was funded by the Spanish 'Ministerio de Ciencia Innovación y Universidades' and FEDER program in the framework of the 'Proyectos de I+D de Generación de Conocimiento del Programa Estatal de Generación de Conocimiento y Fortalecimiento Científico y Tecnológico del Sistema de I+D+i, Subprograma Estatal de Generación de Conocimiento' (ref: PGC2018-095747-B-I00).

Conflicts of Interest: The authors declare no conflict of interest.

\section{Appendix A}

Table A1. Rating of the synchronous machine.

\begin{tabular}{ccc}
\hline Machine Type & 3 Phase Synchronous Machine & 10LCE-132ME1.4 \\
\hline Rated Power & 3.4 & $\mathrm{kVA}$ \\
Rated Voltage & 400 & $\mathrm{~V}$ \\
Rated Power Factor & 0.8 & $\mathrm{~Hz}$ \\
Rated Frequency & 50 & $\mathrm{rpm}$ \\
Speed & 1500 & $\mathrm{~V} / \mathrm{A}$ \\
Rated Field Voltage/Current & $32 / 2.9$ & \\
Stator Slot & 36 & \\
Pole Pairs & 2 & \\
\hline
\end{tabular}

\section{References}

1. Capolino, G.; Romary, R.; Hénao, H.; Pusca, R. State of the Art on Stray Flux Analysis in Faulted Electrical Machines. In Proceedings of the 2019 IEEE Workshop on Electrical Machines Design, Control and Diagnosis (WEMDCD), Piscataway, NJ, USA, 22-23 April 2019; pp. 181-187.

2. Iglesias-Martínez, M.E.; Fernández de Córdoba, P.; Antonino-Daviu, J.; Conejero, J. Detection of Nonadjacent Rotor Faults in Induction Motors via Spectral Subtraction and Autocorrelation of Stray Flux Signals. IEEE Trans. Ind. Appl. 2019, 55, 4585-4594. [CrossRef]

3. Irhoumah, M.; Pusca, R.; Lefevre, E.; Mercier, D.; Romary, R.; Demian, C. Information Fusion With Belief Functions for Detection of Interturn Short-Circuit Faults in Electrical Machines Using External Flux Sensors. IEEE Trans. Ind. Electron. 2018, 65, 2642-2652. [CrossRef]

4. Frosini, L.; Harlişca, C.; Szabó, L. Induction Machine Bearing Fault Detection by Means of Statistical Processing of the Stray Flux Measurement. IEEE Trans. Ind. Electron. 2015, 62, 1846-1854. [CrossRef] 
5. Zamudio-Ramírez, I.; Osornio-Ríos, R.; Trejo-Hernández, M.; Romero-Troncoso, R.; Antonino-Daviu, J. Smart. Sensors to Estimate Insulation Health in Induction Motors via Analysis of Stray Flux. Energies 2019, $12,1658$. [CrossRef]

6. Iglesias-Martínez, M.; Antonino-Daviu, J.; Fernández de Córdoba, P.; Conejero, J. Rotor Fault Detection in Induction Motors Based on Time-Frequency Analysis Using the Bispectrum and the Autocovariance of Stray Flux Signals. Energies 2019, 12, 597. [CrossRef]

7. Irhoumah, M.; Pusca, R.; Lefèvre, E.; Mercier, D.; Romary, R. Diagnosis of induction machines using external magnetic field and correlation coefficient. In Proceedings of the 2017 IEEE 11th International Symposium on Diagnostics for Electrical Machines, Power Electronics and Drives (SDEMPED), Tinos, Greece, 29 August-1 September 2017; pp. 531-536.

8. Panagiotou, P.A.; Arvanitakis, I.; Lophitis, N.; Antonino-Daviu, J.; Gyftakis, K.N. A New Approach for Broken Rotor Bar Detection in Induction Motors Using Frequency Extraction in Stray Flux Signals. IEEE Trans. Ind. Appl. 2019, 55, 3501-3511. [CrossRef]

9. Gyftakis, K.N.; Panagiotou, P.A.; Lee, S.B. The Role of the Mechanical Speed Frequency on the Induction Motor Fault Detection via the Stray Flux. In Proceedings of the 2019 IEEE 12th International Symposium on Diagnostics for Electrical Machines, Power Electronics and Drives (SDEMPED), Toulouse, France, 27-30 August 2019; pp. 201-207.

10. Panagiotou, P.A.; Arvanitakis, I.; Lophitis, N.; Gyftakis, K.N. FEM Study of Induction Machines Suffering from Rotor Electrical Faults Using Stray Flux Signature Analysis. In Proceedings of the 2018 XIII International Conference on Electrical Machines (ICEM), Alexandroupoli, Greece, 3-6 September 2018; pp. 1861-1867.

11. Liu, Z.; Cao, W.; Huang, P.H.; Tian, G.Y.; Kirtley, J.L. Non-invasive winding fault detection for induction machines based on stray flux magnetic sensors. In Proceedings of the 2016 IEEE Power and Energy Society General Meeting (PESGM), Boston, MA, USA, 17-21 July 2016; pp. 1-6.

12. Liu, X.; Miao, W.; Xu, Q.; Cao, L.; Liu, C.; Pong, P.W.T. Inter-Turn Short-Circuit Fault Detection Approach for Permanent Magnet Synchronous Machines Through Stray Magnetic Field Sensing. IEEE Sens. J. 2019, 19, 7884-7895. [CrossRef]

13. Liu, X.; Liu, C.; Pong, P.W.T. Velocity Measurement Technique for Permanent Magnet Synchronous Motors Through External Stray Magnetic Field Sensing. IEEE Sens. J. 2018, 18, 4013-4021. [CrossRef]

14. Cuevas, M.; Romary, R.; Lecointe, J.; Morganti, F.; Jacq, T. Non-invasive detection of winding short-circuit faults in salient-pole synchronous machine. In Proceedings of the 2017 IEEE International Electric Machines and Drives Conference (IEMDC), Miami, FL, USA, 21-24 May 2017; pp. 1-7.

15. Cuevas, M.; Romary, R.; Lecointe, J.; Morganti, F.; Jacq, T. Noninvasive Detection of Winding Short-Circuit Faults in Salient Pole Synchronous Machine with Squirrel-Cage Damper. IEEE Trans. Ind. Appl. 2018, 54, 5988-5997. [CrossRef]

16. Vitek, O.; Janda, M.; Hajek, V. Effects of eccentricity on external magnetic field of induction machine. In Proceedings of the Melecon 2010 15th IEEE Mediterranean Electrotechnical Conference, Valletta, Malta, 26-28 April 2010; pp. 939-943.

17. Zhukova, V.; Corte-Leon, P.; Ipatov, M.; Blanco, J.; Gonzalez-Legarreta, L.; Zhukov, A. Development of Magnetic Microwires for Magnetic Sensor Applications. Sensors 2019, 19, 4767. [CrossRef] [PubMed]

18. Spetzler, B.; Golubeva, E.; Müller, C.; McCord, J.; Faupel, F. Frequency Dependency of the Delta-E Effect and the Sensitivity of Delta-E Effect Magnetic Field Sensors. Sensors 2019, 19, 4769. [CrossRef] [PubMed]

19. Azad, A.; Kim, N. Design and Optimization of an MFL Coil Sensor Apparatus Based on Numerical Survey. Sensors 2019, 19, 4869. [CrossRef] [PubMed]

20. Gyftakis, K.N.; Drif, M.; Cardoso, A.J.M. Thorough Investigation of the Third Current Harmonic in Delta-Connected Induction Motors Suffering from a Stator Inter-Turn Fault. In Proceedings of the IEEE SDEMPED 2015, Guarda, Portugal, 1-4 September 2015.

(C) 2020 by the authors. Licensee MDPI, Basel, Switzerland. This article is an open access article distributed under the terms and conditions of the Creative Commons Attribution (CC BY) license (http://creativecommons.org/licenses/by/4.0/). 